\title{
SPONTANEOUS BREATHING WITH THE BAIN CIRCUIT AT LOW FLOW RATES: A CASE REPORT
}

\author{
W.H. MANSELL
}

THE BAIv cIRcurt was introduced because its simplicity of design and lightness made it especially adaptable for operations on the head and neck. ${ }^{1}$ Under conditions of controlled ventilation, physiological $\mathrm{Pa}_{\mathrm{CO}_{2}}$ values obtain with low flow rates. It has been claimed that the same flow rates can be used with spontaneous respiration, and that the $\mathrm{Pa}_{\mathrm{CO}_{2}}$ still stays within the physiological range. ${ }^{1,2}$

However, it has been determined that rebreathing occurs if the Mapleson-D circuit is used with flow rates equal to or less than minute volume, and that indeed flow rates exceeding twice the minute volume are necessary to prevent rebreathing. ${ }^{3}$ A patient can compensate for some degree of rebreathing by increasing minute volume and, in fact, with controlled ventilation higher than normal tidal and minute volumes are actually doing just that. But the question arises whether under anaesthesia all patients can compensate for the degree of rebreathing which occurs when the Bain circuit is used with low fresh gas flow. Even if they can compensate, is the price which must be paid in increased work of breathing justified? It was my impression that some patients were not compensating well enough and at times exhibited some degree of distress when spontaneous breathing was permitted with the Bain circuit. $\mathrm{Pa}_{\mathrm{CO}_{2}}$ values in the range of 55 to 65 torr were occasionally found. But it was impossible to determine the exact reason for this because of the unknown effect of the narcotic and inhalation agents used.

It has been shown that with the Mapleson-A or Magill circuit rebreathing does not occur with spontaneous respiration if the fresh gas flow is at least 70 per cent of the minute volume. ${ }^{4,5}$ If it were possible to compare the response of a patient to a gas mixture delivered by the Bain circuit at 70 per cent minute volume to the response with a Magill circuit at the same flow rates under the same conditions, then some questions might be answered.

In a clinical setting, one needs a fairly long operation where the operative and anaesthetic conditions remain reasonably constant. Such an opportunity arose at our hospital.

\section{Case Report}

A 29-year-old fit male weighing 80 kilograms was scheduled for finger re-implantation following traumatic amputation. The patient was given a standard premedication of meperidine $50 \mathrm{mg}$ and promethazine $25 \mathrm{mg}$ one hour before the operation. Only mild sedation resulted from this.

Anaesthesia was induced with thiopentone $4 \mathrm{mg} / \mathrm{kg}$ body weight followed by succinycholine $80 \mathrm{mg}$ and tracheal intubation and was then maintained with nitrous oxide (66\%) and oxygen supplemented by 1 per cent halothane.

'Holy Cross Hospital, Calgary, Alberta. 
TABLE I

Effects of the Bain and Magill Circuits Upon Minute Volume and Paco

\begin{tabular}{lcccc}
\hline Circuit & $\begin{array}{c}\text { Fresh gas flow } \\
\text { (liters) }\end{array}$ & $\begin{array}{c}\text { Minute vol. } \\
\text { (liters/min) }\end{array}$ & $\begin{array}{c}\text { Paco, } \\
\text { (torr) }\end{array}$ & Condition \\
\hline (A) Bain & $\begin{array}{c}\mathrm{N}_{2} \mathrm{O} 3.1 \\
\mathrm{O}_{2} 2.5\end{array}$ & 4.3 & 51.3 & 30 min - stable \\
& $\begin{array}{c}\text { (Halothane 1\%) } \\
\text { Same }\end{array}$ & 4.6 & 44.0 & Same \\
(B) Magill & Same & 5.9 & 44.2 & 60 min - stable \\
(C) Bain & Same & 4.0 & 40.3 & Same \\
(D) Magill &
\end{tabular}

After the operation had started he was placed on the Bain circuit with a fresh gas flow of $5600 \mathrm{ml} / \mathrm{min}$ (i.e. $70 \mathrm{ml} / \mathrm{kg}$ ) and this was left for 30 minutes. After that time the minute volume was measured with a Wright respirometer placed at the patient end of the circuit, and simultaneously an arterial blood gas sample was drawn and sent to the laboratory for immediate analysis (see Table I). At this point, the Bain circuit was replaced by a Magill circuit and the patient breathed spontaneously for another 30 minutes under the same conditions. Again minute volume and arterial blood gas measurements were made. Then the patient was returned to the Bain circuit and allowed to continue in that way for more than one hour. Finally this was followed by a similar one-hour period with the Magill circuit. All measurements were done by the same personnel under identical conditions.

\section{Results}

By definition, rebreathing is characterized by an increase in minute or tidal volume in the presence of an elevated or unchanged end-tidal $\mathrm{CO}_{2}$, or by elevated end-tidal $\mathrm{CO}_{2}$ in the presence of increased or unchanged minute or tidal volume. ${ }^{4}$

With the Bain circuit, the measured minute volume and/or the $\mathrm{Pa}_{\mathrm{CO}_{2}}$ was higher than was the case with the Magill circuit. In the situation where $\mathrm{Pa}_{\mathrm{CO}_{2}}$ was similar (Table I), the minute volume was much higher with the Bain circuit (Table I). In case $\mathrm{A}$ the compensation was not adequate and the $\mathrm{Pa}_{\mathrm{CO}_{2}}$ was elevated to 51.3 .

\section{Discussion}

Anaesthetists select circuits to provide adequate oxygenation, to ensure administration of the correct amount of anaesthetic gases and vapours, and to provide adequate removal of carbon dioxide. With a spontaneously breathing patient under anaesthesia, it is felt that the best that can be done is to offer gas free of carbon dioxide at inspiration. ${ }^{6}$

The Bain circuit, a modified Mapleson-D circuit, is a rebreathing circuit at low gas flows. The composition of the inspired mixture during spontaneous respiration depends upon fresh gas flow, length of expiratory pause, and tidal volume. ${ }^{7}$ With low flow rates the clinician is demanding more respiratory effort from the patient but in some cases this may not be adequate. In case of concern for a patient's ability to compensate, one could, of course, increase the fresh gas flow. But with an 
adult this may mean quite high flows. Given present concerns with operating room pollution and cost of anaesthetic gases, high flow rates are not an ideal solution of the problem. Therefore it is my routine to use controlled ventilation whenever the Bain circuit is used. If an anaesthetic with spontaneous respiration is chosen, then another circuit is utilized.

\section{SUMMARY}

A clinical case is presented which suggests that spontaneous respiration with the Bain circuit at low flow rates is associated with rebreathing. Controlled ventilation is advised when the Bain circuit is used.

\section{RÉSUMÉ}

Le cas clinique présenté dans ce travail suggère que le système Bain employé avec respiration spontanée et bas débit de gaz frais, provoque un certain degré de réinspiration. Dans ces conditions, il est recommandé d'employer la ventilation contrôlée.

\section{ACKNOWLEDGMENT}

Thanks to Miss J.M. Carruthers for secretarial assistance.

\section{REFERENCES}

1. BaIN, J.A. \& SPoerel, W.E. A streamlined anaesthetic system. C.A.S.J. 19: 426 (1972).

2. Spoerel, W.E. Correspondence C.A.S.J. 22: 626 (1975).

3. SyKEs, M.K. Rebreathing circuits. B.J.A. 40:666 (1968).

4. KaIN, M.L. \& Nunn, J.F. Fresh gas economics of the Magill circuit. Anaesthesiology 29: 964 (1968).

5. Norman, J., et al. Rebreathing with Magill attachment. Anaesthesia 23: 75 (1968).

6. Gray, T.C. \& NunN, J.F. General anaesthesia. Vol. II, 3rd ed. London; Butterworths, Pp. 699 (1971).

7. DoRsCH, J.A.\& Dorsch, S.E. Understanding anaesthetic equipment. Williams and Wilkins Co. (Baltimore) (1975). 